\title{
Intramolecular Carbocyclization of Allenoate-aldehydes with Hexamethylditin Catalyzed by Palladium Complex: Synthesis of Cyclic Dienes ${ }^{\dagger}$
}

\author{
Wonjae Seong, Suyeon Gong, Seok-Hoon Woo, and Chan-Mo Yu* \\ Department of Chemistry, Sungkyunkwan University, Suwon 440-746, Korea. *E-mail: cmyu@chem.skku.ac.kr \\ Received January 4, 2010, Accepted February 9, 2010
}

Key Words: Allenoate, Carbocyclization, Diene, Lactone, Palladium

Development of new synthetic methods in the construction of cyclic system is an important subject in organic chemistry. Among a variety of synthetic methodologies for the construction of cyclic compounds, chemical transformations involving the use of transition metal catalysts are some of the most attractive methodologies because reactions can directly construct complex molecules from relatively simple starting materials. ${ }^{1}$ As a consequence, many advances in the cyclization mediated by transition metals have been made through a variety of ways in synthetic strategy. ${ }^{2}$ Of particular interest is a cyclization strategy between carbonyl and unsaturated bonds to find practical way of chemical routes for the preparation of lactones mainly because the chemical process could dominate over the classical methods in simple trial. ${ }^{3}$ In this regard, an allene has been proven to be an useful substrate for a variety of transition metal catalytic reactions, particularly for the cyclizations in the construction of carbo- and heterocycles. ${ }^{4}$ Recently, we disclosed our discovery of direct cyclization methods for the synthesis of avenacilolide, ${ }^{5}$ as a part of the allylic transfer strategy utilizing an allene as substrates or intermediates. ${ }^{6}$ To extend this protocol, we reported a cyclization of allenoate-aldehydes 1 mediated by molybdenum carbonyl in the presence of DMSO to direct access naturally occurring canadensolide as shown in Scheme 1. ${ }^{7}$ Although the reaction produced canadensolide and analogues in reasonable yields, products were always contaminated with diasteremers in a 3:1 mixture presumably due to a high reaction temperature.

The characteristic features of this protocol in terms of chemical efficiency through a three component coupling process

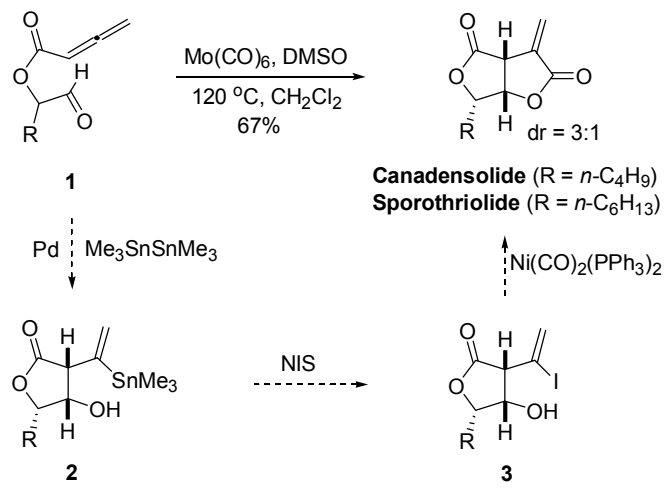

Scheme 1. General strategy

${ }^{\dagger}$ This paper is dedicated to Professor Sunggak Kim on the occasion of his honorable retirement. and structural features of products have encouraged us to carry out further investigations to design synthetic routes, which would improve stereoselectivity and utility of method. As a consequence, we became quite interested in carrying out investigation with stepwise reaction based on our previous studies ${ }^{6 c}$ because it was expected to achieve better diastereoselectivity due to a lower reaction temperature.

With this issue in mind, several allene-aldehydes were prepared by a method developed by our laboratory. ${ }^{7}$ As a starting point, the allenoate-aldehyde $1 \mathrm{a}\left(\mathrm{R}=n-\mathrm{C}_{4} \mathrm{H}_{9}\right)$ was selected as a model substrate because a synthesis of canadensolide was expected from 1a by the three steps sequence from our laboratory. $^{6 c}$

Initial attempts to cyclocarbonylation of 1a under the previous conditions employed for simple allene-aldehydes indicated that the conversion to the corresponding lactone $\mathbf{2 a}$ could not be satisfied in terms of chemical conversion, although carbocyclization was occurred. Reaction produced the dehydrated 4a as a single product (Table 1, entry 1). After surveying numerous conditions for orienting experiments as summarized in Table 1, several key findings were emerged as follows: i) the desired 2 a was not produced under the various conditions appeared in Table 1; ii) the use of Lewis acid additives such as $\mathrm{BF}_{3} \cdot \mathrm{OEt}_{2}$ and $\mathrm{TiCl}_{4}$ resulted in the decomposition; ${ }^{8}$ iii) addition of base $i \mathrm{Pr}_{2} \mathrm{NEt}$ turned out to reduced chemical yield; iv) the use of $\mathrm{CH}_{2} \mathrm{Cl}_{2}$ was superior to other solvents such as toluene,

Table 1. Preliminary investigations with $\mathbf{1 a}$
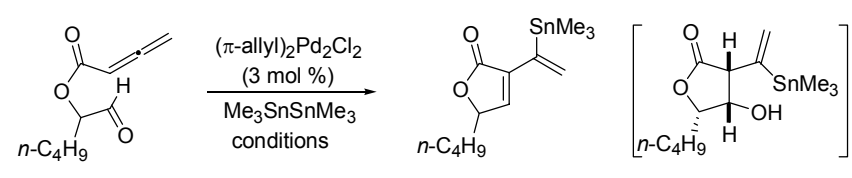

1a

$4 a$

2a

\begin{tabular}{cccccc}
\hline entry & solvent & additive & $\mathrm{T} /{ }^{\circ} \mathrm{C}$ & $\mathrm{t} / \mathrm{h}$ & yield, $\mathbf{4 a}^{a}$ \\
\hline 1 & $\mathrm{CH}_{2} \mathrm{Cl}_{2}$ & none & -40 & 7 & 41 \\
2 & $\mathrm{CH}_{2} \mathrm{Cl}_{2}$ & $\mathrm{BF}_{3} \cdot \mathrm{OEt}_{2}$ & -40 & 7 & decomposed \\
3 & $\mathrm{CH}_{2} \mathrm{Cl}_{2}$ & $\mathrm{TiCl}_{4}$ & -40 & 7 & decomposed \\
4 & $\mathrm{CH}_{2} \mathrm{Cl}_{2}$ & $i \mathrm{Pr}_{2} \mathrm{NEt}$ & -40 & 7 & 23 \\
5 & $\mathrm{CH}_{2} \mathrm{Cl}_{2}$ & none & 20 & 3 & 67 \\
6 & toluene & none & 20 & 7 & 33 \\
7 & ether & none & 20 & 7 & 37 \\
8 & $\mathrm{CF}_{3} \mathrm{Ph}$ & none & 20 & 4 & 48
\end{tabular}

${ }^{a}$ refer to isolated product. 


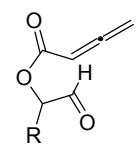

1

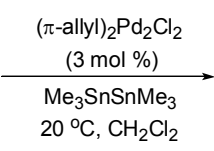

$\begin{array}{ll}\text { a: } \mathrm{R}=n-\mathrm{C}_{4} \mathrm{H}_{9} & 67 \% \\ \text { b: } \mathrm{R}=\mathrm{H} & 71 \% \\ \text { c: } \mathrm{R}=n-\mathrm{C}_{6} \mathrm{H}_{13} & 54 \% \\ \text { d: } \mathrm{R}=\mathrm{Ph} & 47 \%\end{array}$

Scheme 2. Synthesis of diene $\mathbf{4}$ from $\mathbf{1}$

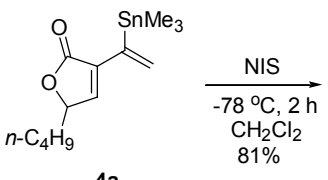

$4 a$

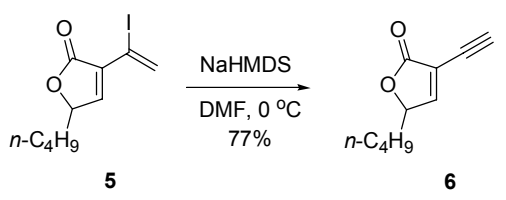

\begin{tabular}{c|c}
$\mathrm{Pd}\left(\mathrm{PPh}_{3}\right)_{4}$ & $\mathrm{~K}_{2} \mathrm{CO}_{3}, \mathrm{MeOH}, 70^{\circ} \mathrm{C}$ \\
$(5 \mathrm{~mol} \%)$ & $67 \%$
\end{tabular}

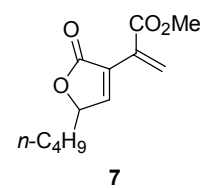

Scheme 3. Functional group transformations of $\mathbf{4}$

ether, and $\mathrm{CF}_{3} \mathrm{Ph}$ in terms of reactivity and chemical yields; $\mathrm{v}$ ) reaction performed at $20^{\circ} \mathrm{C}$ in $\mathrm{CH}_{2} \mathrm{Cl}_{2}$ resulted in the best chemical yield for the synthesis of $\mathbf{4 a}$.

Upon optimal conditions (Table 1, entry 5), the reaction was conducted by a dropwise addition of a mixture of $\mathbf{1 a}$ (1 equiv) and $\mathrm{Me}_{3} \mathrm{SnSnMe}_{3}$ (1.2 equiv) in $\mathrm{CH}_{2} \mathrm{Cl}_{2}$ for 20 min to a solution of $(\pi \text {-allyl })_{2} \mathrm{Pd}_{2} \mathrm{Cl}_{2}(3 \mathrm{~mol} \%)$ at $20^{\circ} \mathrm{C}$ in $\mathrm{CH}_{2} \mathrm{Cl}_{2}$. After $3 \mathrm{~h}$ at $20^{\circ} \mathrm{C}$, the reaction mixture was quenched by addition of saturated aquous $\mathrm{NaHCO}_{3}$. After usual workup procedure and then removal of volatile materials under reduced pressure, final purification was effected by column chromatography to yield $4 \mathbf{a}$ in $67 \%$ yield.

We soon realized that the synthesis of finctionalized cyclic dienes might be useful because the utilization of dienes can be foreseen for many functional group transformations. ${ }^{8}$ With the notion that this approach might lead to a general and efficient method for the synthesis of a cyclic diene 4, we set out to determine the scope to produce structurally various products. Indeed, the method is successful with 1a-d to yield the diene 4a-d as a single adduct, respectively, in moderate to good yields as shown in Scheme 2.
Product 4 is readily amenable for further conversion to synthetically useful compounds by functional group transformations of vinylstannane as depicted in Scheme 3. For example, compound $\mathbf{4 a}$ was converted to 5 by NIS at $-78{ }^{\circ} \mathrm{C}$ in $\mathrm{CH}_{2} \mathrm{Cl}_{2} .{ }^{9}$ Elimination of $\mathbf{5}$ with NaHMDS in DMF yielded the enyne 7. Carbonylation of 6 in the presence of $\operatorname{Pd}(0)$ in the presence of $\mathrm{K}_{2} \mathrm{CO}_{3}$ under $\mathrm{CO}$ pressure in $\mathrm{MeOH}$ gave 8 in good yield. ${ }^{10}$

In summary, this communication describes synthetic routes to the cyclic diene 4 from allenoate-aldehydes 1 with hexamethylditin catalyzed by palladium complex in a general and efficient way which promises to be synthetically useful. Studies are in progress to incorporate with diene into multi-cyclic compounds by cycloaddition reaction related to a core skeleton of biologically active natural products.

Acknowledgments. Generous financial support from the Korea Research Foundation (KRF-2006-312-C00234; KRF2005-005-J11901) and the Korea Science \& Engineering Foundation (R01-2007-000-20315-0) is gratefully acknowledged.

\section{References and Notes}

1. (a) Nakamura, I.; Yamamoto, Y. Chem. Rev. 2004, 104, 2127. (b) Zeni, G.; Larock, R. C. Chem. Rev. 2006, 106, 4644.

2. (a) Trost, B. M.; Toste, F. D.; Pinkerton, A. B. Chem. Rev. 2001, 101, 2067. (b) Aubert, C.; Buisine, O.; Malacria, M. Chem. Rev. $2002,102,813$.

3. Reviews, see: (a) Trost, B. M. Acc. Chem. Res. 2002, 35, 695. (b) Ma, S. Eur. J. Org. Chem. 2004, 1175.

4. Mandai, T. In Modern Allene Chemistry, Vol. 2; Krause, N., Hashmi, A. S. K., Eds.; Wiley-VCH: Weinheim, 2004; pp 925-972.

5. Yu, C.-M.; Youn, J.; Jung, J. Angew. Chem. Int. Ed. 2006, 45, 1553.

6. (a) Yu, C.-M.; Hong, Y.-T.; Lee, J. J. Org. Chem. 2004, 69, 8506. (b) Yu, C.-M.; Hong, Y.-T.; Yoon, S.-K.; Lee, J. Synlett 2004, 1695. (c) Yu, C.-M.; Youn, J.; Lee, M.-K. Org. Lett. 2005, 7, 3733. (d) Yu, C.-M.; Youn, J.; Jung, H.-K. Bull. Korean Chem. Soc. 2006, 27, 463. (e) Ko, K.-J.; Kim, S. H.; Kim, Y.; Min, D.; Yu, C.-M. Bull. Korean Chem. Soc. 2007, 28, 1921. (f) Kim, S. H.; Oh, S.-J.; Ho, P.-S.; Kang, S.-C.; O, K.-J.; Yu, C.-M. Org. Lett. 2008, 10, 265.

7. Kwon, J.; Gong, S.; Woo, S.-H.; Yu, C.-M. Bull. Korean Chem. Soc. 2009, 30, 773 .

8. For example: Katritzky, A. R., Taylor, R. J. K., Eds., In Comprehensive Functional Group Transformations II; Elsevier Pergamon: Amsterdam, 2005; pp 427-1310.

9. (a) Britton, R. A.; Piers, E.; Patrick, B. O. J. Org. Chem. 2004, 69, 3068. (b) Paley, R. S.; De Dios, A.; Estroff, L. A.; Lafontaine, J. A.; Montero, C.; McCulley, D. J.; Rubio, M. B.; Ventura, M. P.; Weers, H. L.; de la Pradilla, R. F.; Castro, S.; Dorado, R.; Morente, M. J. Org. Chem. 1997, 62, 6326.

10. Martin, L. D.; Stille, J. K. J. Org. Chem. 1982, 47, 3630. 